\title{
Molecular detection and genetic characterisation of pathogenic Theileria, Anaplasma and Ehrlichia species among apparently healthy sheep in central and western Kenya
}

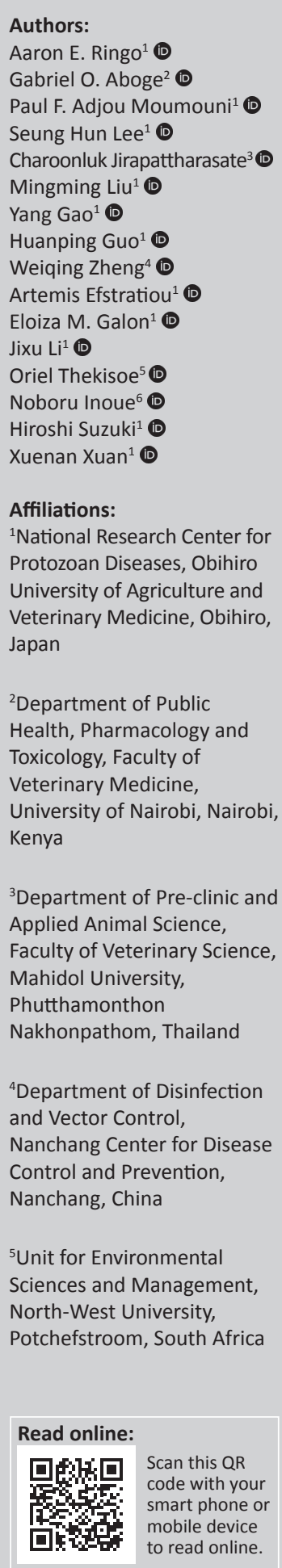

Tick-borne diseases (TBDs) caused by Theileria, Babesia, Anaplasma and Ehrlichia species are common in tropical and subtropical regions. In this study, we investigated the presence and genetic diversity of Theileria spp., Anaplasma ovis, B. ovis, E. ruminantium and Anaplasma spp. in sheep from the Machakos and Homa Bay counties of Kenya. In order to improve the diagnosis and control of ovine TBDs, a total of 76 blood samples from apparently healthy sheep were screened using a polymerase chain reaction (PCR). The assays were conducted using primers based on Theileria spp. $18 S$ rRNA, Anaplasma ovis Major surface protein-4 (AoMSP4), B. ovis $18 S$ rRNA, E. ruminantium pCS20 and Anaplasma spp. $16 S$ rRNA. The overall infection rates for Theileria spp., A. ovis, E. ruminantium and Anaplasma spp. were 39/76 $(51.3 \%), 26 / 76(34.2 \%), 6 / 76(7.9 \%)$ and $31 / 76(40.8 \%)$, respectively. The overall co-infection was $47 / 76(61.8 \%)$. All Theileria spp. positive samples were confirmed to be of Theileria ovis on sequencing. A phylogenetic analysis of the $18 \mathrm{~S} r \mathrm{RNA}$ gene sequences of $\mathrm{T}$. ovis revealed that all isolates of this study clustered with T. ovis sequences extracted from the GenBank suggesting this gene is highly conserved. E. ruminantium pCS20 sequences were in the same clade on the phylogenetic tree. However, three AoMSP4 sequences from this study appeared in the same clade, while one sequence formed a separate branch revealing genetic divergence. The $16 S$ rRNA sequencing revealed uncharacterised Anaplasma spp. and A. ovis. The phylogenetic analyses of the uncharacterised Anaplasma spp. revealed that the two sequences from this study appear in an independent clade from other sequences extracted from the GenBank. This study provides important information regarding the occurrence of tick-borne pathogens and their degree of genetic diversity among sheep in Kenya, which is useful for the diagnosis and control of TBDs.

Keywords: sheep; PCR; Kenya; tick-borne pathogens; phylogenetic analysis.

\section{Introduction}

Tick-borne diseases (TBDs) caused by Theileria, Babesia, Anaplasma and Ehrlichia are common in tropical and subtropical regions of the world where there is increased interaction of hosts, pathogens and vectors (Bilgic et al. 2017). Over the years, limited attention of TBD studies has been directed to sheep and goats compared to cattle (Yin et al. 2007). However, small ruminants are becoming important in a number of countries as far as socio-economic importance is concerned. Therefore, more attention is now being directed towards pathogens of sheep and goats (Bilgic et al. 2017).

The tick-borne pathogens of small ruminants include Theileria ovis, T. separata, T. lestoquardi, T. sp. OT1, T. sp. OT3, T. luwenshuni and T. recondita which cause theileriosis. Babesia ovis and B. motasi cause babesiosis. Anaplasma ovis causes anaplasmosis, whereas A. phagocytophilum causes tickborne fever and Ehrlichia ruminantium causes ehrlichiosis (Bilgic et al. 2017). T. lestoquardi, B. ovis, B. motasi, A. phagocytophilum and E. ruminantium are considered to be pathogenic, while the rest

${ }^{6}$ Obihiro University of Agriculture and Veterinary Medicine, Obihiro, Japan

Corresponding author: Xuenan Xuan, gen@obihiro.ac.jp

Dates: Received: 12 Mar. 2018 | Accepted: 15 Jan. 2019 | Published: 13 June 2019

How to cite this article: Ringo, A.E., Aboge, G.O., Adjou Moumouni, P.F., Hun Lee, S., Jirapattharasate, C., Liu, M. et al., 2019, 'Molecular detection and genetic characterisation of pathogenic Theileria, Anaplasma and Ehrlichia species among apparently healthy sheep in central and western Kenya', Onderstepoort Journal of Veterinary Research 86(1), a1630. https://doi.org/10.4102/ojvr.v86i1.1630

Copyright: @ 2019. The Authors. Licensee: AOSIS. This work is licensed under the Creative Commons Attribution License. 
with the exception of the recently detected T. sp. OT1 and T. sp. OT3 are non-pathogenic in sheep and goats (Razmi \& Yaghfoori 2003; Schnittger et al. 2000; Uilenberg 1995). The pathogenicity of $T$. sp. OT1 and T. sp. OT3 do not have conclusive evidence (Yin et al. 2007).

Economic losses incurred from the TBDs include mortality, production losses, veterinary costs and tick control (Jonsson, Bock \& Jorgensen 2008). In sheep, T. ovis and A. ovis manifest themselves as sub-clinical infections (Bilgic et al. 2017). Animals that survive the acute phase of infection develop a life-long carrier state, which is associated with significant production and economic losses (Gharbi et al. 2006; Uilenberg 1995). Therefore, the pathogens regarded as less pathogenic should equally be considered important, as they continuously infect ticks when they are in the carrier state, resulting in new infection to uninfected animals (Razmi \& Yaghfoori 2003).

The eastern part of Africa is one of the three regions of subSaharan Africa which are considered to be highly populated by sheep and other livestock (Hanotte et al. 2000). Regardless of the large population of sheep in the region, little information is available on the presence and genetic diversity of tick-borne pathogens. This study was conducted to fill in this information gap. Blood samples were collected from sheep in Machakos and Homa Bay counties in Kenya and tested for the occurrence and genetic diversity of ovine tickborne pathogens using PCR and sequencing.

\section{Materials and methods}

\section{Study area}

Blood samples were collected from sheep in Machakos and Homa Bay counties (Figure 1). Machakos is located in central Kenya, about $63 \mathrm{~km}$ south-east of Nairobi. The local climate is semi-arid with hilly terrain and an altitude of $1000 \mathrm{~m}-2100 \mathrm{~m}$ above sea level. The climate of this area is temperate and subtropical whereby temperatures are modified by altitude. The area has summer rainfall, while the vegetation is savannah, and rain starts at the end of March to May.

Homa Bay county is located in western Kenya along Lake Victoria. The county is near mount Homa and Ruma National Park, located $420 \mathrm{~km}$ south-west of Nairobi. The climate is semi-arid with temperatures ranging from $26^{\circ} \mathrm{C}$ in the coldest months (April and November) to $34{ }^{\circ} \mathrm{C}$ during the hottest months (January and March). The county receives an average rainfall of $1100 \mathrm{~mm}$, long rains in March to May and short rains in September to November (Climate-data.org 2018).

The farmers in both counties are mainly pastoralists with large groups of livestock involving cattle, sheep and goats. The breeds of sheep are mainly Red Maasai.

\section{Sample collection and DNA extraction}

A total of 76 blood samples were collected in August 2011 (dry season) from clinically healthy sheep, using sterile needles

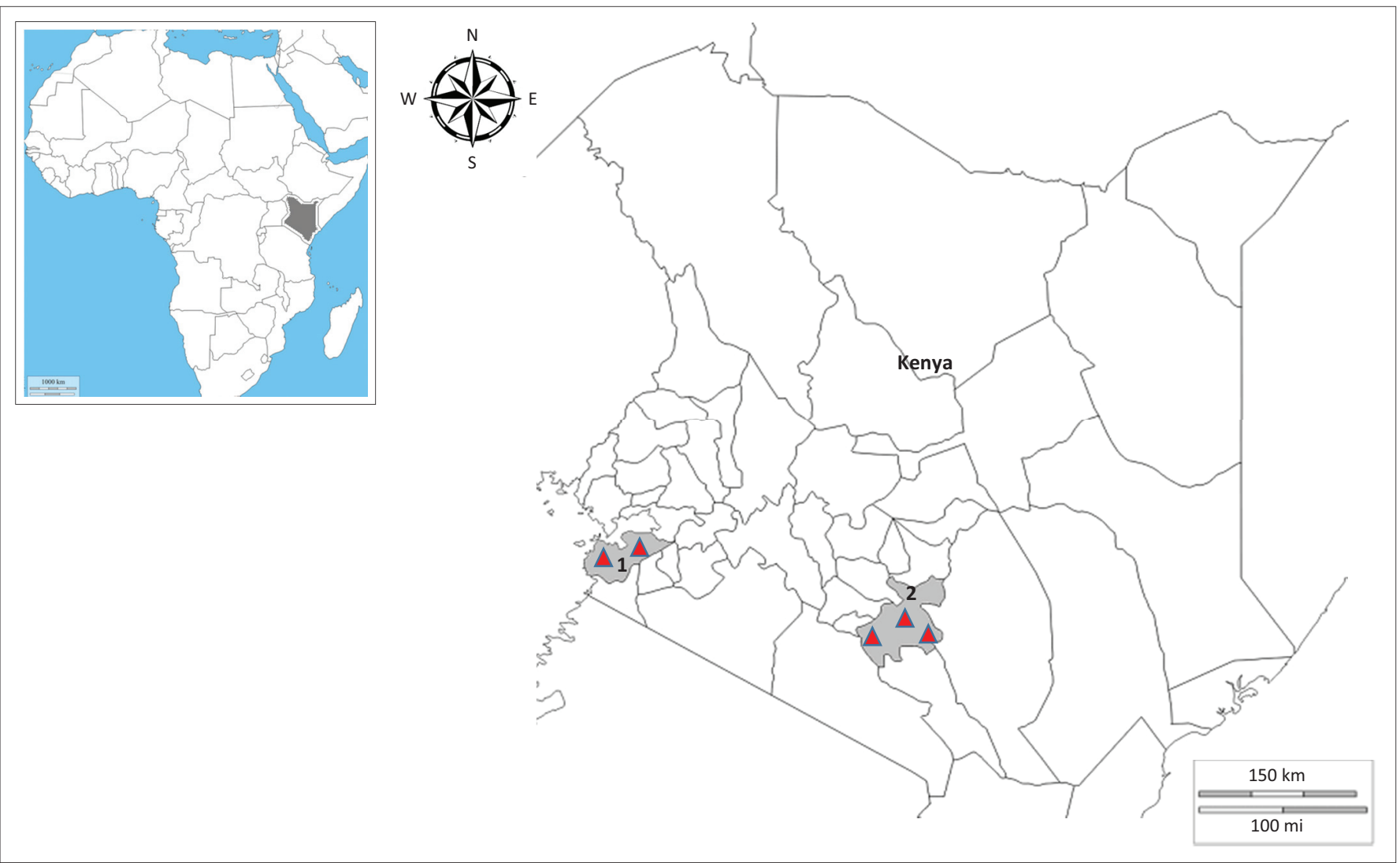

$\mathrm{km}$, kilometres; mi, metres.

Source: Ringo, A.E., Adjou Moumouni, P.F., Taioe, M., Jirapattharasate, C., Liu, M., Wang, G. et al., 2018, 'Molecular analysis of tick-borne protozoan and rickettsial pathogens in small ruminants from two South African provinces', Parasitology International 67, 144-149. https://doi.org/10.1016/j.parint.2017.11.002

FIGURE 1: A map of Kenya showing the two counties where samples were collected: (1) Homa Bay in western Kenya and (2) Machakos in central Kenya. The red triangles are locations of sample collection farms. 
and EDTA-coated vacutainer tubes (Boenmed, Jiangsu, China). An average of $3 \mathrm{~mL}-5 \mathrm{~mL}$ of blood was drawn from the jugular vein of the animal and refrigerated until transported to the laboratory. Fifty-two and 24 samples were collected in Machakos and Homa Bay counties, respectively. Samples were collected randomly in five locations and mostly from pastoralist farms. Male and female sheep of around 2 years of age and above were targeted. DNA was extracted from $200 \mu \mathrm{L}$ of blood using the QIAamp DNA Blood Mini Kit (Qiagen, Hilden, Germany), following manufacturer's protocol, and stored at $-30^{\circ} \mathrm{C}$ until the time of use.

\section{Molecular detection of tick-borne pathogens}

All samples were screened using PCR with primers obtained from previous studies for Theileria spp. 18S rRNA, B. ovis $18 S$ rRNA, A. ovis Major surface protein 4 (AoMSP4), Anaplasma spp. $16 S$ rRNA and E. ruminantium $p$ CS20 genes (Table 1). The reaction mixture had a final volume of $10 \mu \mathrm{L}$, containing $0.5 \mathrm{mM}$ of each primer, $1 \mu \mathrm{L}$ of $10 \times$ standard Ex taq buffer, $1 \mu \mathrm{L}$ of dNTP mix and $0.1 \mu \mathrm{L}$ of Ex taq polymerase (Takara - Shiga, Japan), $1 \mu \mathrm{L}$ of DNA template and $5.9 \mu \mathrm{L}$ of double distilled water. The double distilled water was used as a negative control, while positive controls were positive samples from a previous study (Ringo et al. 2018). Polymerase chain reactions were run in a thermal cycler (Bio Rad, Hercules, CA, United States [US]). Polymerase chain reaction conditions consisted of initial denaturation at $95^{\circ} \mathrm{C}$ for 5 minutes, followed by 35 cycles of denaturation for $1 \mathrm{~min}$ at $94^{\circ} \mathrm{C}, 1 \mathrm{~min}$ annealing at differing temperatures which can be found in Table 1 and 1.30 min extension at $72{ }^{\circ} \mathrm{C}$. The final extension was set to $10 \mathrm{~min}$ at $72{ }^{\circ} \mathrm{C}$. The same PCR conditions were used for Anaplasma spp. PCR and nested PCR. As for E. ruminantium, the reaction mixture was performed in a semi-nested PCR consisting of initial denaturation for $3 \mathrm{~min}$ at $94^{\circ} \mathrm{C}$, followed by 25 cycles of denaturation for 0.30 seconds at $94{ }^{\circ} \mathrm{C}$, annealing for 0.45 seconds at $61{ }^{\circ} \mathrm{C}$ and $1 \mathrm{~min}$ at $72{ }^{\circ} \mathrm{C}$ extension. The final extension was done at $72{ }^{\circ} \mathrm{C}$ for $10 \mathrm{~min}$. The PCR products were electrophoresed on a $2 \%$ agarose gel and then stained with ethidium bromide and viewed under UV transilluminater.

\section{Cloning and sequencing}

For sequencing, 3-5 positive samples per detected pathogen were randomly selected. Amplicons were purified using a QIAquick Gel Extraction Kit (Qiagen, Germany) per the manufacturer's protocol. The concentration of the extracts was checked using the Nano Drop 2000 spectrophotometer. The template $(6 \mu \mathrm{L})$ was ligated into a pGEM-T Easy vector $(2 \mu \mathrm{L})$ (Promega, US), with T4 DNA ligase and restriction buffer (each $1 \mu \mathrm{L}$ ) added and incubated at $16^{\circ} \mathrm{C}$ for 3 hours and then at $4{ }^{\circ} \mathrm{C}$ overnight. Transformation of the plasmid into Escherichia coli $\mathrm{DH} 5 \alpha$ competent cells (prepared in-house) was performed. Lysogeny broth (LB) was added and incubated at $37^{\circ} \mathrm{C}$ in a shaker incubator for $1 \mathrm{~h}$ and then inoculated on LB agar plates and incubated at $37{ }^{\circ} \mathrm{C}$ overnight. Colonies were picked and put in LB broth with an antibiotic (Ampicillin) $50 \mu \mathrm{g} / \mathrm{mL}$ (Wako, Saitama, Japan) incubated at $37^{\circ} \mathrm{C}$ overnight in a shaker incubator. Plasmid was extracted using the NucleoSpin ${ }^{\circledR}$ Plasmid QuickPure (Macherey-Nagel-Germany) kit. The samples were sequenced using a BigDye Terminator v3.1 Cycle Sequencing Kit (Applied Biosystems, US) and a 3100 Genetic Analyzer (Applied Biosystems, Foster city, Calafornia, US). The alignment of the sequences was performed using Lasergene v14.1 (DNASTAR, Madison, WI, US). The nucleotide sequence identities and similarities were determined by using a GenBank BLASTn analysis.

\section{Phylogenetic analysis}

The sequences obtained in this study were compared with sequences deposited in the GenBank by phylogenetic analysis using MEGA version 7.0 software (Kumar, Stecher \& Tamura 2016). The maximum likelihood method was used to construct phylogenetic trees for T. ovis, A. ovis, E. ruminantium and uncharacterised Anaplasma spp. Bootstrap analysis with 1000 replications was used to estimate the confidence of the nodes and branches of the trees.

\section{Nucleotide sequence accession numbers}

Sequences obtained in this study were deposited in the GenBank database of the National Center for Biotechnology Information using BankIt. The sequences were assigned the following accession numbers: MF360021 to MF360025 for T. ovis 18S rRNA; MF360026 to MF360029 for A. ovis MSP4; MG637125 to MG637127 for uncharacterised Anaplasma spp. $16 S$ rRNA; and MG544303 to MG544305 for E. ruminantium pCS20.

\section{Ethical considerations}

The owners of the selected farms were informed about the study and provided their approval for sample collection from their sheep. All the procedures were approved and carried out

TABLE 1: List of primers used for polymerase chain reaction assays.

\begin{tabular}{|c|c|c|c|c|c|c|}
\hline \multirow[t]{2}{*}{ Target gene } & \multirow[t]{2}{*}{ Assay } & \multicolumn{2}{|c|}{ Primer sequences $\left(5^{\prime} \rightarrow 3^{\prime}\right)$} & \multirow{2}{*}{$\begin{array}{l}\text { Fragment } \\
\text { (bp) }\end{array}$} & \multirow{2}{*}{$\begin{array}{l}\text { Annealing } \\
\text { temp }\left({ }^{\circ} \mathrm{C}\right)\end{array}$} & \multirow[t]{2}{*}{ Reference } \\
\hline & & Forward & Reverse & & & \\
\hline Babesia ovis (18S rRNA) & PCR & TGGGCAGGACCTTGGTTCTTCT & CCGCGTAGCGCCGGCTAAATA & 549 & 62 & (Aktas, Altay \& Dumanli 2007) \\
\hline Anaplasma ovis (AoMSP4) & PCR & TGAAGGGAGCGGGGTCATGGG & GAGTAATTGCAGCCAGGCACTCT & 347 & 62 & (Alessandra \& Santo 2012) \\
\hline \multirow[t]{2}{*}{ Anaplasma spp.(16S rRNA) } & PCR & GGTTTAATTCGATGCAACGCGA & CGTATTCACCGTGGCATG & 430 & $78-69$ & (Bekker et al. 2002) \\
\hline & $\mathrm{nPCR}$ & GGTTTAATTCGATGCAACGCGA & GCTCAGCCTTGCGACGT & 335 & $78-69$ & (Simuunza et al. 2010) \\
\hline \multirow[t]{2}{*}{ Ehrlichia ruminantium ( $p C S 20$ ) } & PCR & ACTAGTAGAAATTGCACAATCYAT & RCTDGCWGCTTTYTGTTCAGCTAK & 400 & 61 & (Farougou et al. 2012) \\
\hline & $\mathrm{nPCR}$ & ACTAGTAGAAATTGCACAATCYAT & TGATAACTTGGWGCRRGDARTCCTT & 278 & 61 & - \\
\hline \multirow[t]{2}{*}{ Theileria spp. (18S rRNA) } & PCR & GAAACGGCTACCACATCT & AGTTTCCCCGTGTTGAGT & 778 & 55 & Cao et al. 2013 \\
\hline & $\mathrm{nPCR}$ & TTAAACCTCTTCCAGAGT & TCAGCCTTGCGACCATAC & 581 & 55 & - \\
\hline
\end{tabular}

PCR, polymerase chain reaction; $\mathrm{NPCR}$, nested Polymerase Chain Reaction; bp, base pair. 
according to ethical guidelines for the use of animal samples permitted by Obihiro University of Agriculture and Veterinary Medicine (permit for animal experiment: 280080, DNA experiment 1219-2; Pathogen: 2015727).

\section{Results}

\section{Overall infection rates}

Polymerase chain reaction results revealed that $59 / 76$ (77.6\%) sheep were infected with at least one pathogen. Seventeen sheep $(22.4 \%)$ were not infected with any of the screened pathogens. Theileria spp. had an overall infection rate of $39 / 76$ (51.3\%), A. ovis $26 / 76$ (34.2\%), E. ruminantium $6 / 76$ (7.9\%) and uncharacterised Anaplasma spp. 31/76 (40.8\%). Theileria ovis was the only Theileria species identified following the sequencing of all PCR-positive Theileria spp., while for Anaplasma spp., the uncharacterised Anaplasma spp. and A. ovis were identified. Meanwhile, B. ovis and T. lestoquardi were not detected in this study.

\section{Infection rates based on location}

In Homa Bay, $20 / 24$ (83.3\%) sheep were infected with at least one pathogen, while $4 / 24(16.7 \%)$ were not infected with any of the pathogens screened. The infection rates for each pathogen in Homa Bay were 13/24 (54.2\%), 8/24 (33.3\%), 2/24 (8.3\%) and 10/24 (41.7\%) for T. ovis, A. ovis, E. ruminantium and uncharacterised Anaplasma spp., respectively. In Machakos, $39 / 52$ (75\%) sheep were infected with at least one pathogen. Thirteen of the $52(25 \%)$ sheep were not infected with any of the screened pathogens. The infection rates for each pathogen in Machakos were 26/52 (50\%), $18 / 52(34.6 \%), 4 / 52(7.7 \%)$ and $14 / 52$ (26.9\%) for T. ovis, A. ovis, E. ruminantium and uncharacterised Anaplasma spp., respectively.

\section{Mixed infections}

Several sets of co-infections were revealed in this study (Table 2). Multiple infections were found in 47/76 (61.8\%) samples. Theileria ovis was the pathogen most frequently associated with multiple infections $(35 / 76 ; 46.1 \%)$ followed closely by $A$. ovis $(34 / 76 ; 44.7 \%$ ) (Table 2$)$. Theileria ovis $+A$. ovis co-infection had the highest overall prevalence. A triple infection (A. ovis + T. ovis + uncharacterised Anaplasma spp.) with an overall prevalence of $6 / 76(7.9 \%)$ was revealed in this study (Table 2).

\section{Comparative sequence analysis}

The PCR products of all the T. ovis, A. ovis and E. ruminantium isolated in this study were of the expected sizes of $520 \mathrm{bp}$ (base pair), $347 \mathrm{bp}$ and $279 \mathrm{bp}$, respectively. The three uncharacterised Anaplasma spp. amplified products were of different sizes ( $398 \mathrm{bp}, 367 \mathrm{bp}$ and $344 \mathrm{bp}$ ). The percentage of identity among the five $T$. ovis $18 \mathrm{~S} r R N A$ nucleotide sequences of this study (MF360021 - MF360025) ranged from 99.61\% to $100.00 \%$. These sequences shared $100 \%$ identity with previous sequences deposited in GenBank from Sudan (AY260171 and MG333457) and Tanzania (AY260174). Furthermore, the four A. ovis MSP4 nucleotide sequences of this study (MF360026 MF360029) shared 97.98\% - 100.00\% nucleotide identity and had $98 \%$ nucleotide identity with the other sequences from Tunisia (KY659324, KY659320, KM285220 and KC432643). Meanwhile, the three E. ruminantium pCS20 sequences isolated in this study (MG544303 - MG544305) shared a nucleotide identity of $99.64 \%$ and had $100 \%$ sequence identity with other GenBank sequences from Ethiopia (GU797236), Benin (KX356089), the Ivory Coast (KX356090) and Cameroon (JQ039914 and JQ039939). As for uncharacterised Anaplasma spp. $16 S$ rRNA, the three sequences from this study (MG637125-MG637127) shared 100\% nucleotide identity and showed 100\% nucleotide identity with sequences from Japan (AY969011) and the United States (KJ942183).

\section{Phylogenetic analysis}

Phylogenetic trees of T. ovis, A. ovis, uncharacterised Anaplasma spp. and E. ruminantium were constructed based on $18 S$ rRNA, MSP4, $16 S$ rRNA and $p C S 20$ gene sequences, respectively, which have been generated in this study and those downloaded from GenBank. The T. ovis sequences from this study clustered with the T. ovis sequences from the GenBank, making a separate clade from other Theileria species (Figure 2). Three A. ovis MSP-4 sequences from this study were in the same clade, while one sequence formed a separate branch (Figure 3). Similarly, for E. ruminantium, all the three sequences from this study were located in the same clade (Figure 4). Meanwhile, the uncharacterised Anaplasma spp. sequences of this study appeared in the same clade separated from other Anaplasma sequences from the GenBank (Figure 5).

\section{Discussion}

Despite the wide distribution of ovine TBDs in tropical and subtropical regions of the world (Ros-García et al. 2013),

TABLE 2: Mixed infections detected in sheep in this study.

\begin{tabular}{|c|c|c|c|c|c|c|c|c|c|c|c|c|}
\hline \multirow[t]{4}{*}{ Pathogens } & \multicolumn{12}{|c|}{ County } \\
\hline & \multicolumn{4}{|c|}{ Homa Bay $(n=24)$} & \multicolumn{4}{|c|}{ Machakos $(n=52)$} & \multicolumn{4}{|c|}{ Overall $(n=76)$} \\
\hline & \multicolumn{2}{|c|}{ Infected } & \multicolumn{2}{|c|}{ Uninfected } & \multicolumn{2}{|c|}{ Infected } & \multicolumn{2}{|c|}{ Uninfected } & \multicolumn{2}{|c|}{ Infected } & \multicolumn{2}{|c|}{ Uninfected } \\
\hline & $N$ & $\%$ & $N$ & $\%$ & $N$ & $\%$ & $N$ & $\%$ & $N$ & $\%$ & $N$ & $\%$ \\
\hline Theileria ovis + Anaplasma ovis & 4 & 16.7 & 20 & 83.3 & 14 & 26.9 & 38 & 73.1 & 18 & 23.7 & 58 & 76.3 \\
\hline Anaplasma ovis + uncharacterised Anaplasma spp. & 3 & 12.5 & 21 & 87.5 & 5 & 9.6 & 47 & 90.4 & 8 & 10.5 & 68 & 89.5 \\
\hline Anaplasma ovis + Ehrlichia ruminantium & 2 & 8.3 & 22 & 91.7 & 0 & 0.0 & 52 & 100.0 & 2 & 2.6 & 74 & 97.4 \\
\hline Theileria ovis + uncharacterised Anaplasma spp. & 5 & 20.8 & 19 & 79.2 & 6 & 11.5 & 46 & 88.5 & 11 & 14.5 & 65 & 85.5 \\
\hline Uncharacterised Anaplasma spp. + Ehrlichia ruminantium & 2 & 8.3 & 22 & 91.7 & 0 & 0.0 & 52 & 100.0 & 2 & 2.6 & 74 & 97.4 \\
\hline Anaplasma ovis + Theileria ovis + uncharacterised Anaplasma spp. & 2 & 8.3 & 22 & 91.7 & 4 & 7.7 & 48 & 92.3 & 6 & 7.9 & 70 & 92.1 \\
\hline
\end{tabular}




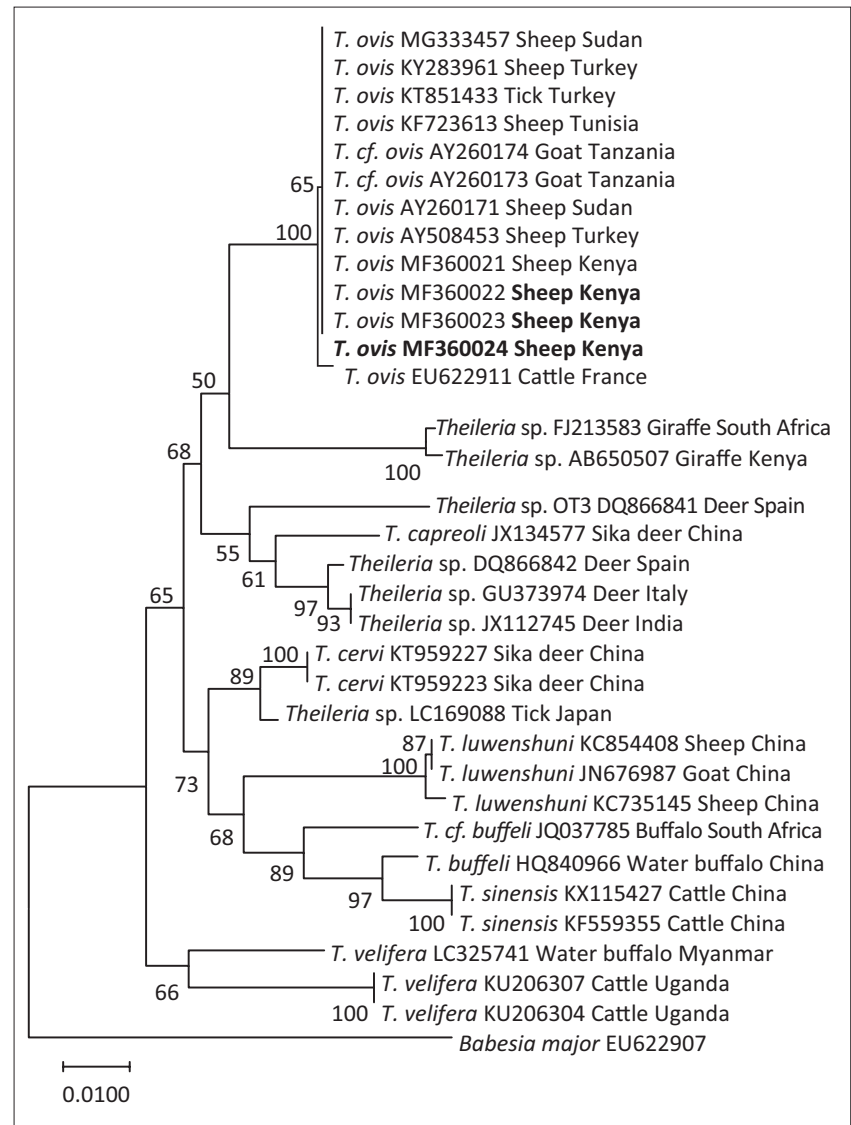

Source: Ringo, A.E., Adjou Moumouni, P.F., Taioe, M., Jirapattharasate, C., Liu, M., Wang, G. et al., 2018, 'Molecular analysis of tick-borne protozoan and rickettsial pathogens in small ruminants from two South African provinces', Parasitology International 67, 144-149. https://doi.org/10.1016/j.parint.2017.11.002

FIGURE 2: Phylogenetic analysis of Theileria ovis based on $18 S$ rRNA. The sequences generated in this study are shown in bold font. Numbers at the nodes represent the percentage of occurrence of clades in 1000 bootstrap replication of the taxa. The $18 S$ rRNA gene sequence of Babesia major (EU622907) was used as an outgroup.

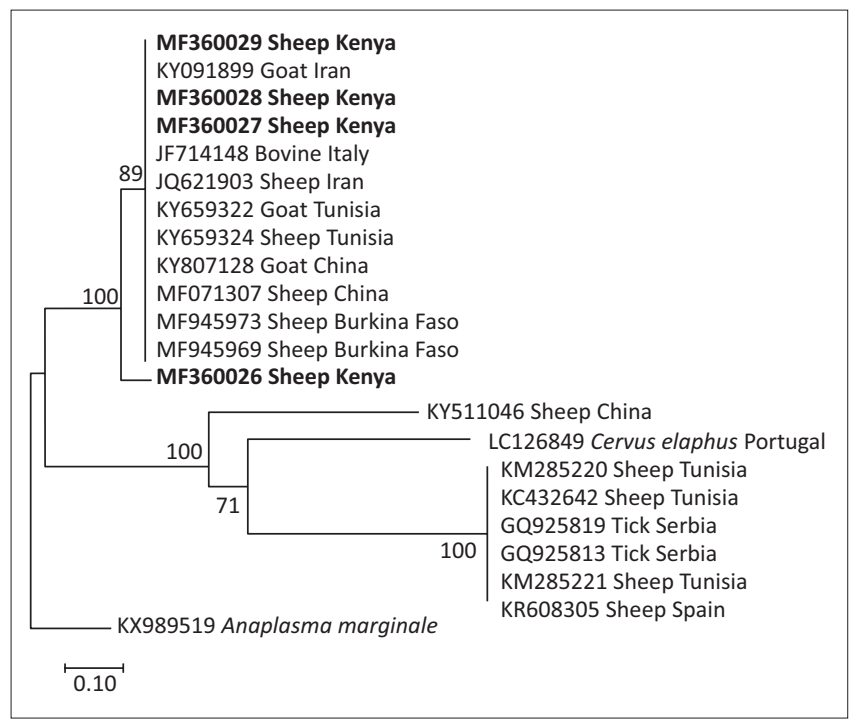

Source: Ringo, A.E., Adjou Moumouni, P.F., Taioe, M., Jirapattharasate, C., Liu, M., Wang, G. et al., 2018, 'Molecular analysis of tick-borne protozoan and rickettsial pathogens in smal ruminants from two South African provinces', Parasitology International 67, 144-149. https://doi.org/10.1016/j.parint.2017.11.002

FIGURE 3: Phylogenetic analysis of Anaplasma ovis based on AoMSP4. The sequences determined in this study are shown in bold font. Numbers at the nodes represent the percentage of occurrence of clades in 1000 bootstrap replication of the taxa. The MSP4 gene sequence of Anaplasma marginale (KX989519) was used as an outgroup.

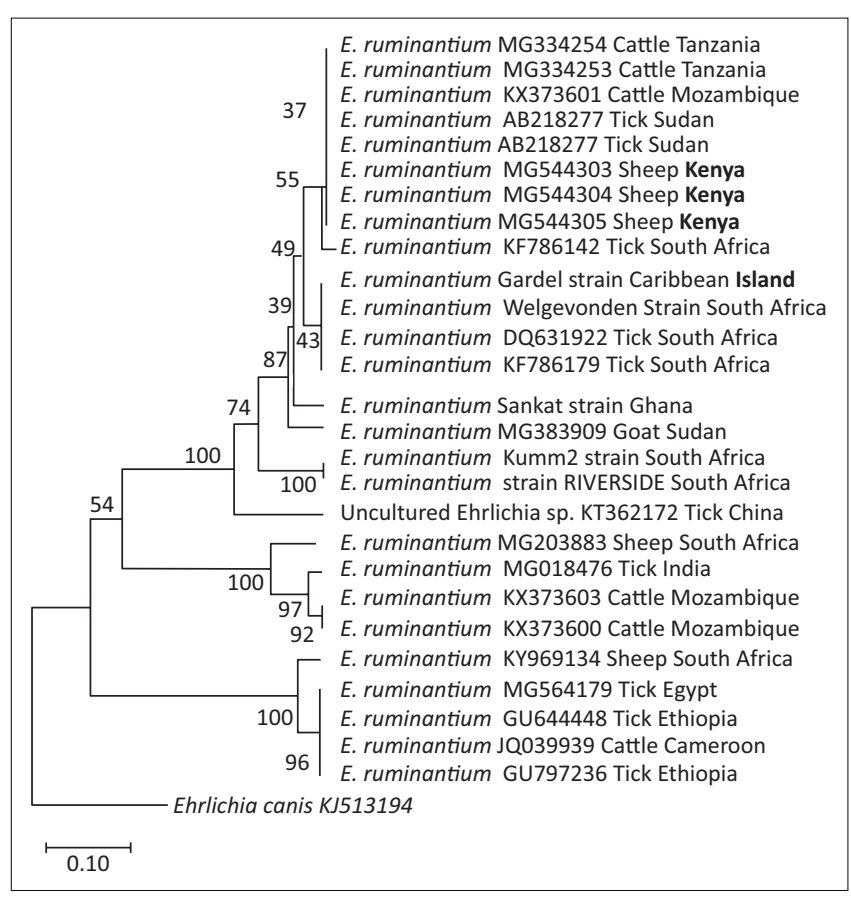

Source: Ringo, A.E., Adjou Moumouni, P.F., Taioe, M., Jirapattharasate, C., Liu, M., Wang, G. et al., 2018, 'Molecular analysis of tick-borne protozoan and rickettsial pathogens in small ruminants from two South African provinces', Parasitology International 67, 144-149. https://doi.org/10.1016/j.parint.2017.11.002

FIGURE 4: Phylogenetic analysis of Ehrlichia ruminantium based on $p$ CS20. The sequences in bold font are from this study. The numbers at the nodes represent the percentage of occurrence of clades in 1000 bootstrap replication of the taxa. The pCS20 gene sequence of Ehrlichia chaffeensis (CP007477) was used as an outgroup.

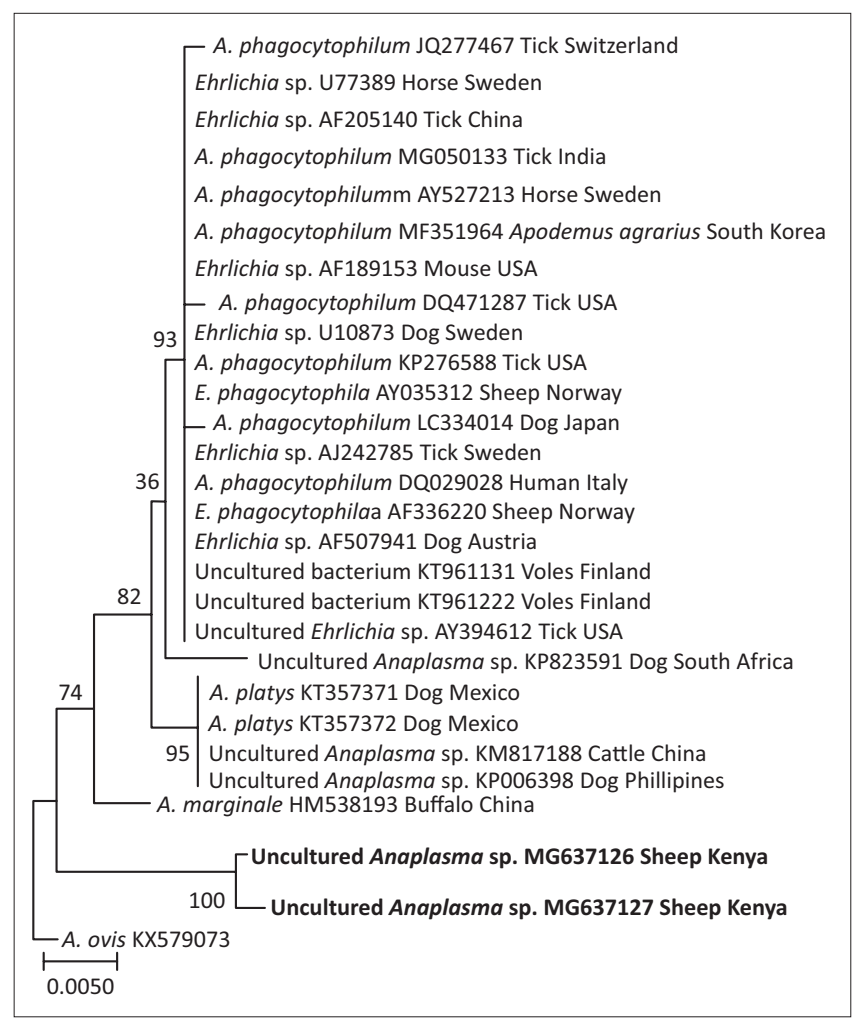

sp., species.

Source: Ringo, A.E., Adjou Moumouni, P.F., Taioe, M., Jirapattharasate, C., Liu, M., Wang, G. et al., 2018, 'Molecular analysis of tick-borne protozoan and rickettsial pathogens in small
ruminants from two South African provinces', Parasitology International 67, 144-149. https://doi.org/10.1016/j.parint 2017.11.002

FIGURE 5: Phylogenetic analysis of uncharacterised Anaplasma spp. based on $16 S$ SRNA. The sequences in bold font are from this study. The numbers at the nodes represent the percentage of occurrence of the clades in 1000 bootstrap replication of the taxa. The 16S rRNA gene sequence of Anaplasma ovis (KX579073) was used as an outgroup. 
and how important they are in livestock improvement (Bilgic et al. 2017; Jongejan \& Uilenberg 1994; Jonsson et al. 2008), very little information is available regarding their presence and distribution (Ros-García et al. 2013). In the present study, we performed molecular detection and analysis of tick-transmitted protozoan and rickettsial pathogens in blood samples of sheep collected from Homa Bay and Machakos counties, Kenya. The following pathogens were detected: T. ovis, A. ovis, E. ruminantium and uncharacterised Anaplasma spp.

Theileriosis in sheep can be caused by several Theileria spp. (Berggoetz et al. 2014) - in this study, only T. ovis was detected $(51.3 \%)$. The study revealed $T$. ovis as the most prevalent pathogen, which is in contrast to previous studies (Mwamuye et al. 2017; Omondi et al. 2017; Wamuyu et al. 2015) that did not detect this pathogen in Kenya. However, Adjou Moumouni et al. (2015) reported this pathogen in cattle reared in the town of Ngong which is in Kajiado, a county bordering Machakos county in the south-west. The prevalence of $T$. ovis was compared to other studies from neighbouring countries. In Ethiopia, Gebrekidan et al. (2014) reported a prevalence of $92 \%$, while El Imam et al. (2016) reported a prevalence of $88.6 \%$ in the Sudan. Normally, T. ovis is known to cause a benign type of theileriosis and is less pathogenic to sheep (Razmi et al. 2003; Schnittger et al. 2000; Uilenberg 1995). This protozoa is considered of low economic importance in sheep (Mtshali et al. 2016). However, it cannot be neglected, as it can cause disease in sheep under stressful situations.

The $18 S$ rRNA gene sequence of $T$. ovis from this study shared high identity $(100 \%)$ with isolates from neighbouring countries including the Sudan (AY260171 and MG333457) and Tanzania (AY260174). This could be because of the movement of animals in huge numbers in this region by the pastoralists, which leads to an increased probability of animals from different areas crossing over in search of grazing pastures. This could lead to transmission of ticks from one herd to the other. Moreover, the phylogenetic tree showed all 18S rRNA sequences (Figure 2) in this study in the same cluster with other T. ovis sequences extracted from the GenBank, which suggest that similar genotypes are circulating in the field.

Anaplasmosis caused by A. ovis generally is considered to cause sub-clinical symptoms in sheep, although this disease has been reported to be prevalent in high severity in Bighorn sheep (Renneker et al. 2013; Tibbitts et al. 1992). Acute disease tends to be associated with stress factors such as co-infection, hot weather, deworming, vaccination, heavy tick burden, long distance transportation and animal movement (Renneker et al. 2013). In this study, a prevalence of $34.2 \%$ was detected for this pathogen - this is higher than previously reported in Kenya by Omondi et al. (2017). However, this pathogen was not detected in the Maasai Mara and Shimba Hills National Reserves (Mwamuye et al. 2017; Wamuyu et al. 2015) located in the south-west of Kenya about $150 \mathrm{~km}$ from the study areas. Data from other studies in Africa showed a high prevalence of $A$. ovis in Tunisia (Belkahia et al.
2014), Algeria (Aouadi 2017) and South Africa (Ringo et al. 2018). These observations suggest that $A$. ovis has a wide distribution in different geographical areas of Africa. However, in Kenya and other parts of sub-Saharan Africa, large numbers of sheep are owned by the pastoralists, who travel long distances daily in sunny weather, searching for pastures and water (Byaruhanga et al. 2016). This potentially leads to animal stress and eventually may result in severe disease. The low production of local breeds of sheep owned by pastoralists could be associated with this infection as they are easily exposed to stress and to pathogens that are endemic in sub-Saharan Africa (Bilgic et al. 2017).

Phylogenetic analysis of A. ovis MSP4 revealed that the three sequences isolated in this study appear in the same clade with other sequences extracted from the GenBank (Figure 3), while the remaining sequence from this study formed a separate branch (Figure 3). This shows considerable genetic divergence of sequences isolated from this study, revealing that different genotypes of this parasite are circulating in the field.

Ehrlichia ruminantium, transmitted by ticks of the genus Amblyomma, causes heartwater in domestic and wild ruminants in sub-Saharan Africa, Madagascar and some Caribbean islands (Allsopp 2010). The disease is one of the major obstacles to improving livestock production in Africa (Cangi et al. 2017). In this study, E. ruminantium was detected in sheep from both Machakos and Homa Bay counties, with an overall occurrence of $7.9 \%$ - this supports the previous studies in Kenya (Omondi et al. 2017) that reported a similar prevalence. The presence of several Amblyomma tick species in Kenya, including Amblyomma variegatum, has been reported by Omondi et al. (2017), which suggests that ovine ehrlichiosis is endemic in Kenya. In the phylogenetic analysis, all the three sequences obtained in this study (Figure 4) clustered together, which shows that the gene is highly conserved in the study areas.

The uncharacterised Anaplasma sp. was detected in this study. This study reports the pathogen for the first time in Kenya. The overall prevalence is $31.6 \%$ from both sampled counties. Phylogenetic analyses showed the two sequences of this bacterium clustered together (Figure 5).

The overall co-infection rate in this study was $61.8 \%$, with T. ovis showing high association in co-infection. The co-infection (T. ovis + A. ovis) $(27.3 \%)$ was the most common and this could be associated with a relatively higher infection rate of the two pathogens in this study. Moreover, the two pathogens share the same vector, Rhipicephalus evertsi evertsi, which has been reported in Kenya by Omondi et al. (2017). In the two counties, the co-infections were relatively similar, except for T. ovis + A. ovis co-infection which had a prevalence of $4 \%$ and $14 \%$ in Homa Bay and Machakos, respectively. This could be attributed to the fact that the two pathogens had higher infection rates in both counties and Machakos had a higher number of samples compared to Homa Bay. 
In this study, all pathogens were detected from apparently healthy animals, which suggest that sheep in Kenya have established an enzootic stability status against these pathogens. It shows that animals were infected at the early stages of their lives and developed immunity against the detected pathogens. These animals carry the pathogens without displaying any clinical signs, but they continuously transmit the pathogens to ticks and eventually to new animals.

Babesia ovis and Theileria lestoquardi were not detected in this study, which supports the previous study (Omondi et al. 2017), although further studies with greater coverage may be needed to ascertain their absence.

\section{Conclusion}

The results obtained in this study indicate the occurrence and diversity of T. ovis, A. ovis, E. ruminantium and uncharacterised Anaplasma spp. in sheep from Machakos and Homa Bay counties. Mixed infections are common in the study area and, therefore, disease diagnosis can be complex. Consequently, proper diagnostic tests are required for accurate diagnosis. Further studies covering larger sample size and wider geographical coverage, including blood work, more epidemiological data and tick collection are required to estimate the risk factors associated with these diseases and their economic importance.

\section{Acknowledgements}

This study was supported by a Grant-in-Aid for Scientific Research from the Ministry of Education, Culture, Sports, Science and Technology of Japan and a grant from the Japan Society for the Promotion of Science Core-to-Core Program Japan (26304036 and 17F17105). The authors thank the state veterinarians and animal health technicians in Kenya for collecting blood samples in the study areas.

\section{Competing interests}

The authors declare that they have no financial or personal relationships that may have inappropriately influenced them in writing this article.

\section{Authors' contributions}

The collection of samples was supervised by G.O.A. The research was designed by A.E.R., P.F.A.M., X.X. and N.I. Laboratory experiments were performed by A.E.R., S.H.L., M.L., Y.G., H.G., A.E., E.M.G. and J.L. The manuscript was written by A.E.R., P.F.A.M., C.J., W.Z., O.T., H.S. and X.X.

\section{References}

Adjou Moumouni, P.F., Aboge, G.O., Terkawi, M.A., Masatani, T., Cao, S., Kamyingkird, K. et al., 2015, 'Molecular detection and characterization of Babesia bovis, Babesia bigemina, Theileria species and Anaplasma marginale isolated from cattle in Kenya', Parasites and Vectors 8(1), 496. https://doi.org/10.1186/s13017-015-1106-9

Aktas, M., Altay, K. \& Dumanli, N., 2007, 'Determination of prevalence and risk factors for infection with Babesia ovis in small ruminants from Turkey by polymerase chain reaction', Parasitology Research 100(4), 797-802. https://doi.org/10.1007/ s00436-006-0345-2
Alessandra, T. \& Santo, C., 2012, 'Tick-borne diseases in sheep and goats: Clinical and diagnostic aspects', Small Ruminant Research 106(suppl.), S6-S11. https://doi. org/10.1016/j.smallrumres.2012.04.026

Allsopp, B.A., 2010, 'Natural history of Ehrlichia ruminantium', Veterinary Parasitology 167(2-4), 123-135. https://doi.org/10.1016/j.vetpar.2009.09.014

Aouadi, A., Leulmi, H., Boucheikhchoukh, M., Benakhla, A., Raoult, D. \& Parola, P., 2017, 'Molecular evidence of tick-borne hemoprotozoan-parasites (Theileria ovis and Babesia ovis) and bacteria in ticks and blood from small ruminants in northern Algeria', Comparative Immunology, Microbiology and Infectious Diseases 50, 34-39. https://doi.org/10.1016/j.cimid.2016.11.008

Bekker, C.P., De Vos, S., Taoufik, A., Sparagano, O.A. \& Jongejan, F., 2002, 'Simultaneous detection of Anaplasma and Ehrlichia species in ruminants and detection of Ehrlichia ruminantium in Amblyomma variegatum ticks by reverse line blot hybridization', Veterinary Microbiology 89(2-3), 223-238. https://doi.org/ 10.1016/s0378-1135(02)00179-7

Belkahia, H., Said, M.B., Hamdi, S., Yahiaoui, M., Gharbi, M., Mhadhbi, M. et al., 2014, 'First molecular identification and genetic characterization of Anaplasma ovis in sheep from Tunisia', Small Ruminant Research 121, 404-410. https://doi. org/10.1016/j.smallrumres.2014.07.009

Berggoetz, M., Schmid, M., Ston, D., Wyss, V., Chevillon, C., Pretorius, A.M. et al., 2014, 'Tick-borne pathogens in the blood of wild and domestic ungulates in South Africa: Interplay of game and livestock', Ticks and Tick-Borne Diseases 5(2), 166-175. https://doi.org/10.1016/j.ttbdis.2013.10.007

Bilgic, H.B., Bakırcı, S., Kose, O., Unlu, A.H., Hacılarlıoglu, S., Eren, H. et al., 2017 'Prevalence of tick-borne haemoparasites in small ruminants in Turkey and diagnostic sensitivity of single-PCR and RLB', Parasites and Vectors 10(1), 211. https://doi.org/10.1186/s13071-017-2151-3

Byaruhanga, C., Collins, N.E., Knobel, D., Chaisi, M.E., Vorster, I., Steyn, H.C. et al., 2016 'Molecular investigation of tick-borne haemoparasite infections among transhumant zebu cattle in Karamoja Region, Uganda', Veterinary Parasitology: Regional Studies and Reports 3-4, 27-35. https://doi.org/10.1016/j.vprsr.2016.06.004

Cangi, N., Pinarello, V., Bournez, L., Lefrancois, T., Albina, E., Neves, L. et al., 2017 'Efficient high-throughput molecular method to detect Ehrlichia ruminantium in ticks', Parasites \& Vectors 10, 566. https://doi.org/10.1186/s13071-017-2490-0

Cao, S.N., Zhang, S., Jia, L., Xue, S., Yu, L., Kamyingkird, K. et al., 2013, 'Molecular detection of Theileria species in sheep from northern China', Journal of Veterinary Medical Science 75(9), 1227-1230. https://doi.org/10.1292/jvms.13-0028Climate-data.org, 2018, Climate data for cities worldwide, viewed 15 December 2018, from https:// en.climate-data.org/.

El Imam, A.H., Hassan, S.M., Gameel, A.A., El Hussein, A.M., Taha, K.M., Oosthuizen, M.C., 2016, 'Molecular identification of different Theileria and Babesia species infecting sheep in Sudan', Annals of Parasitology 62(1), 47-54. https://doi. org/10.17420/ap6201.31

Farougou, S., Adakal, H., Biguezoton, A.S. \& Boko, C., 2012, 'Prévalence de I' infection d'Amblyomma variegatum par Ehrlichia ruminantium dans les élevages extensifs du Bénin', Revue Medecine Veterinaire 163(5), 261-266.

Gebrekidan, H., Hailu, A., Kassahun, A., Rohoušová, I., Maia, C., Talmi-Franck, D. et al., 2014, 'Theileria infection in domestic ruminants in northern Ethiopia', Veterinary Parasitology 200(1-2), 31-38. https://doi.org/10.1016/j.vetpar.2013.11.017

Gharbi, M., Sassi, L., Dorchies, P. \& Darghouth, M.A., 2006, 'Infection of calves with Theileria annulata in Tunisia: Economic analysis and evaluation of the potential benefit of vaccination', Veterinary Parasitology 137(3-4), 231-241. https://doi. org/10.1016/j.vetpar.2006.01.015

Hanotte, O., Tawah, C.L., Bradley, D.G., Okomo, M., Verjee, Y., Ochieng, J. et al., 2000 'Geographic distribution and frequency of a taurine Bos taurus and an indicine
Bos indicus Y specific allele amongst sub-Saharan African cattle breeds', Molecular Bos indicus Y specific allele amongst sub-Saharan African cattle breeds', Molecul
Ecology 9(4), 387-396. https://doi.org/10.1046/j.1365-294x.2000.00858.x

Jongejan, F. \& Uilenberg, G., 1994, 'Ticks and control methods', Revue scientifique et technique (International Office of Epizootics) 13(4), 1201-1226. https://doi. org/10.20506/rst.13.4.818

Jonsson, N.N., Bock, R.E. \& Jorgensen, W.K., 2008, 'Productivity and health effects of anaplasmosis and babesiosis on Bos indicus cattle and their crosses, and the effects of differing intensity of tick control in Australia', Veterinary Parasitology 155(1-2), 1-9. https://doi.org/10.1016/j.vetpar.2008.03.022.

Kumar, S., Stecher, G. \& Tamura, K., 2016, 'MEGA7: Molecular Evolutionary Genetics Analysis Version 7.0 for bigger datasets', Molecular Biology and Evolution 33(7), 1870-1874. https://doi.org/10.1093/molbev/msw054

Mtshali, K., Khumalo, Z., Nakao, R., Grab, D.J., Sugimoto, C. \& Thekisoe, O., 2016 'Molecular detection of zoonotic tick-borne pathogens from ticks collected from ruminants in four South African provinces', The Journal of veterinary medical science/The Japanese Society of Veterinary Science 77(12), 1573-1579. https:// doi.org/10.1292/jvms.15-0170

Mwamuye, M.M., Kariuki, E., Omondi, D., Kabii, J., Odongo, D., Masiga, D. et al., 2017 'Novel Rickettsia and emergent tick-borne pathogens: A molecular survey of tick' and tick-borne pathogens in Shimba Hills National Reserve, Kenya', Ticks and TickBorne Diseases 8(2), 208-218. https://doi.org/10.1016/j.ttbdis.2016.09.002

Omondi, D., Masiga, D.K., Fielding, B.C., Kariuki, E., Ajamma, Y.U., Mwamuye, M.M et al., 2017, 'Molecular detection of tick-borne pathogen diversities in ticks from livestock and reptiles along the shores and adjacent islands of lake Victoria and lake Baringo, Kenya', Frontiers in Veterinary Science 4(June), 1-15. https://doi. org/10.3389/fvets.2017.00073

Razmi, G. \& Yaghfoori, S., 2013, 'Molecular surveillance of Theileria ovis, Theileria lestoquardi and Theileria annulata infection in sheep and ixodid ticks in Iran', Onderstepoort Journal of Veterinary Research 80(1), 5. https://doi.org/10.4102/ojvr.v80i1.635.

Razmi, G.R., Hosseini, M. \& Aslani, M.R., 2003, 'Identification of tick vectors of ovine theileriosis in an endemic region of Iran', Veterinary Parasitology 116(1), 1-6. $\mathrm{https}: / /$ doi.org/10.1016/s0304-4017(03)00254-1 
Renneker, S., Abdo, J., Salih, D.E., Karagenç, T., Bilgiç, H., Torina, A. et al., 2013, 'Can Anaplasma ovis in small ruminants be neglected any longer?', Transboundary and Emerging Diseases 60(suppl. 2), 105-112. https://doi.org/10.1111/tbed.12149

Ringo, A.E., Adjou Moumouni, P.F., Taioe, M., Jirapattharasate, C., Liu, M., Wang, G. et al., 2018, 'Molecular analysis of tick-borne protozoan and rickettsial pathogens in small ruminants from two South African provinces', Parasitology International 67, 144-149. https://doi.org/10.1016/j.parint.2017.11.002

Ros-García, A., Barandika, J.F., Garcia-Perez, A.L., Juste, R.A. \& Hurtado, A., 2013 'Assessment of exposure to piroplasms in sheep grazing in communal mountain pastures by using a multiplex DNA bead-based suspension array', Parasites and Vectors 6(1), 1-11. https://doi.org/10.1186/1756-3305-6-277

Schnittger, L., Yin, H., Jianxun, L., Ludwig, W., Shayan, P., Rahbari, S. et al., 2000 'Ribosomal small-subunit RNA gene-sequence analysis of Theileria lestoquardi and a Theileria species highly pathogenic for small ruminants in China' Parasitology Research 86(5), 352-358, viewed 25 February 2018, from https:// link.springer.com
Simuunza, M., Weir, W., Courcier, E., Tait, A. \& Shiels, B., 2010, 'Epidemiological analysis of tick-borne diseases in Zambia', Veterinary Parasitology 175, 331-342. https://doi.org/10.1016/j.vetpar.2010.09.027

Tibbitts, T., Goff, W., Forayt, W. \& Stiller, D., 1992, 'Susceptibility of two rocky mountain bighorn sheep to experimental infection with Anaplasma ovis', Journal of Wildlife Diseases 28(1), 125-129. https://doi.org/10.7589/0090-3558-28.1.125

Uilenberg, G., 1995, 'International collaborative research: Significance of tick-borne hemoparasitic diseases to world animal health', Veterinary Parasitology 57(1-3), 19-41. https://doi.org/10.1016/0304-4017(94)03107-8

Wamuyu, L., Obanda, V., Kariuki, D., Gakuya, F., Makanda, M., Otiende, M. et al., 2015 'Molecular detection and characterization of Theileria Infecting Wildebeest (Connochaetes taurinus) in the Maasai Mara National Reserve, Kenya', Pathogens 4(3), 626-638. https://doi.org/10.3390/pathogens4030626

Yin, H., Schnittger, L., Luo, J., Seitzer, U. \& Ahmed, J.S., 2007, 'Ovine theileriosis in China: A new look at an old story', Parasitology Research 101(suppl. 2), 191-195. https://doi.org/10.1007/s00436-007-0689-2 